\title{
A Descriptive Study of the Practice Patterns of Massage New Zealand Massage Therapists
}

\author{
Joanna M. Smith, PhD, ${ }^{1}$ S. John Sullivan, $\mathrm{PhD},{ }^{2}$ G. David Baxter, DPhil ${ }^{2}$ \\ ${ }^{I}$ New Zealand Massage Therapy Research Centre, Southern Institute of Technology, and \\ ${ }^{2}$ Centre for Physiotherapy Research, School of Physiotherapy, University of Otago, New Zealand
}

Background: Massage therapy has grown in popularity, yet little is known globally or in New Zealand about massage therapists and their practices.

Purpose and Setting: The aims of this study were to describe the practice patterns of trained Massage New Zealand massage therapists in New Zealand private practice, with regard to therapist characteristics; practice modes and settings, and therapy characteristics; referral patterns; and massage therapy as an occupation.

Research Design and Participants: A survey questionnaire was mailed to 66 trained massage therapist members of Massage New Zealand who were recruiting massage clients for a concurrent study of massage therapy culture.

Results: Most massage therapists were women $(83 \%)$, NZ European (76\%), and holders of a massage diploma qualification $(89 \%)$. Massage therapy was both a full- $(58 \%)$ and part-time $(42 \%)$ occupation, with the practice of massage therapy being the only source of employment for $70 \%$ of therapists. Nearly all therapists $(94 \%)$ practiced massage for more than 40 weeks in the year, providing a median of $16-20$ hours of direct client care per week. Most massage therapists worked in a "solo practice" $(58 \%)$ and used a wide and active referral network. Almost all therapists treated musculoskeletal symptoms: the most common client issues or conditions treated were back pain/problem (99\%), neck/shoulder pain/problem $(99 \%)$, headache or migraine $(99 \%)$, relaxation and stress reduction $(96 \%)$, and regular recovery or maintenance massage $(89 \%)$. The most frequent client fee per treatment was NZ\$60 per hour in a clinic and NZ\$1 per minute at a sports event or in the workplace. Therapeutic massage, relaxation massage, sports massage, and trigger-point therapy were the most common styles of massage therapy offered. Nearly all massage therapists $(99 \%)$ undertook client assessment; $95 \%$ typically provided self-care recommendations; and $32 \%$ combined other complementary and alternative medicine therapies with their massage consultations.

Conclusions: This study provides new information about the practice of massage therapy by trained massage therapists. It will help to inform the massage industry and other health care providers, potential funders, and policymakers about the provision of massage therapy in the NZ health care system.

KEYWORDS: Complementary and alternative therapies, massage therapy, New Zealand, integrative care, practice patterns

\section{INTRODUCTION}

Massage therapy (MT) is characterized by the application of purposeful and systematic touch, a collection of skills, and a variety of styles and techniques ${ }^{(1)}$ to "physically manipulate the body's soft tissues for the purpose of effecting a desirable change in the individual"(2) (p. 5). In ancient times and throughout the world, massage was often considered to be a medicinal practice, and it has been practiced in many forms ${ }^{(3,4)}$. Today, MT still incorporates a variety of styles (for example, relaxation or clinical massage) (5-7), and it is used to treat symptoms associated with a wide range of chronic ${ }^{(8)}$, clinical $^{(7,9,10)}$ and sporting $^{(11-13)}$ conditions. Massage may be used as an adjunct or standalone therapy by a number of health care providers such as nurses ${ }^{(14,15)}$, physiotherapists (physical therapists) $^{(16,17)}$, other complementary and alternative medicine (CAM) providers ${ }^{(18,19)}$, and massage therapists ${ }^{(20)}$. In some countries, including the United States, employment opportunities for MT exist within the sports, wellness, corporate, and health care settings ${ }^{(4,21)}$; MT is also increasingly common in hospitals ${ }^{(22,23)}$ and hospices ${ }^{(24)}$.

Within New Zealand, MT is not an established part of the national public health care system, and it is not generally reimbursed by private health insurance companies or funded by the Accident Compensation Corporation, New Zealand's state-funded accident insurance company. However, MT is among the many growing CAM modalities ${ }^{(25)}$ and is accessed as a standalone therapy, with data showing that, during a 12-month period in $2002-2003,9.1 \%$ of adult New Zealanders reported having visited a massage therapist ${ }^{(25)}$. 
The practice of MT is unregulated by New Zealand law, and there are a range of educational standards and levels ${ }^{(26)}$. Since 1985, New Zealand has seen the establishment of a small number of voluntary professional bodies to support the education and profile of massage therapists ${ }^{(27)}$. In 2006, two of the larger professional bodies combined to form Massage New Zealand (MNZ) which is the only voluntary national professional body specifically for MT. In 2008, MNZ represented approximately 250 massage therapists at either the certified massage therapist (CMT) or the remedial massage therapist (RMT) levels ${ }^{(27)}$. Certified massage therapists hold a training qualification in relaxation massage and most commonly have 600 hours of massage training; RMTs hold a training qualification in relaxation and remedial, deep tissue, or other advanced clinical styles of massage, and their massage training can vary from 1200 hours to 3600 hours. Members of MNZ have met the internal requirements for training (education/qualification); are bound by a code of ethics, a scope of practice, and a complaints procedure; and are subject to requirements for continuing professional development ${ }^{(28)}$.

Massage therapists with or without MT training also practice in New Zealand. The Department of Labour recently reported 1272 people employed as "massage therapists" in 2006, a 54\% growth since 2001 and a $451 \%$ growth since $1996^{(29)}$. However, the Department of Labour data are not clear as to the training or professional status of the 1272 "massage therapists." Because of a lack of regulation, no unified database of massage practices or therapists exists, and the best option for specifically accessing trained and practicing massage therapists and their clients was to use the membership list of MNZ.

The aim of the current study was to describe the practice patterns of MT in New Zealand, focusing on members of MNZ. Little is known about the practice or characteristics of massage therapists in New Zealand (for example, styles of massage practiced, modes and settings of practice). The data presented here were obtained as part of a larger study of the culture of MT practice and the drivers for repeat use of MT in New Zealand.

\section{METHODS}

\section{Sampling and Eligibility of Massage Therapists}

New Zealand-based trained massage therapists (men and women) from established MT practices with repeat clients constituted the target group for the larger study and the concurrent therapist survey. The sampling frame was the membership list of MNZ (both membership categories - CMT and RMTwere included). Members of MNZ were included if they had a massage volume of at least 5 massages in a typical week, had provided at least 5 clients with a minimum of 2 sessions in the last 3 months, were 16 years of age or older, and had the motivation to see the study through to its completion. Therapists who were not currently practicing or were not comfortable with written English were excluded. In addition, massage therapists trained in other health professions and providing massage as an adjunct to physiotherapy, osteopathy, chiropractic, or nursing, and those working in a massage parlor were excluded. These inclusion/ exclusion criteria were related to the objectives of the parent study (Smith JM. Massage therapy services for health needs: drivers, utilisation, culture of care, and practice patterns of massage therapy in NZ. PhD thesis; University of Otago, Dunedin, NZ; 2009).

\section{Survey Instrument Development}

A questionnaire (36 items, open and closed responses, 6 single-sided pages) was designed to collect information related to therapist characteristics; practice modes and settings; and MT techniques, assessment, and reassessment practices. A list of topic areas were initially compiled from the research objectives; the literature (Osborn CE. Complementary and alternative medicine and the treatment of rheumatic diseases: focusing on aromatherapy. $\mathrm{PhD}$ thesis; Coventry University, Coventry, UK; 2001; Quinn F. Complementary and alternative medicine in the treatment of low back pain, with a focus on reflexology. $\mathrm{PhD}$ thesis; University of Ulster, Belfast, UK; 2006) ${ }^{(7,8,20,25,30-35)}$; consultation with Māori (NZ indigenous peoples); collegial discussions; and from the words and themes derived from a telephone focus-group study of massage clients $(36,37)$ and massage therapists (Smith JM. Massage therapy services for health needs: drivers, utilisation, culture of care, and practice patterns of massage therapy in NZ. PhD thesis; University of Otago, Dunedin, NZ; 2009). The questionnaire was further developed using an expert panel (researchers, massage therapists, and methodologists) and was subsequently pilot tested. The University of Otago Human Ethics Committee approved the final questionnaire.

\section{Recruitment and Data Collection}

Of the approximately 250 massage therapists listed as members of MNZ, 92 who met the inclusion criteria volunteered for the parent study. They were recruited using four approaches (e-mail, the "members only" forum page of the MNZ website, the MNZ newsletter, and their publicly listed "find a therapist" web page) and invited to participate. The self-report postal questionnaire was distributed during May September 2008; massage therapists were asked to complete the questionnaire at their leisure and return it to the researcher within 7 days in the addressed freepost envelope. On receipt, completed questionnaires were manually coded, and the codes were entered into data files using the Statistical Package 
for the Social Sciences software (version 15: SPSS, Chicago, IL, USA). Results were analyzed using descriptive statistics (for example, means, medians, frequency counts).

\section{RESULTS}

\section{Participation Rates}

From among 92 questionnaires distributed, 66 responses were received (response rate of $71.7 \%$; 7 withdrew, 19 failed to respond). Of the 18 designated NZ regions, 12 were represented. Respondents came from North and South Island rural and urban regions, and major city areas were well represented; only the regions of Taranaki, Wanganui, Manawatu, Wairarapa, Marlborough, and West Coast were not represented.

\section{Therapist Profiles}

Most participants were female (83.3\%), NZ European $(75.8 \%)$, and $28-64$ years of age [mean: $45.8 \pm 8.7$ years (standard deviation)]. The number of years of MT practice ranged from 0.5 years to 34 years (mean: $9.0 \pm 6.0$ years; median: 7.0 years). The therapists' MT qualifications ranged from a certificate to a baccalaureate degree, with a post-high school diploma (from a polytechnic or other tertiary training provider) being the most commonly reported qualification (89.4\%). Qualifications were primarily obtained in New Zealand (93.9\%). About half (51.5\%) had received their highest MT qualification in the preceding 5 years. Participants also commonly held other non-massage related qualifications (65.6\%): 9 (13.6\%) held a current annual practicing certificate (or professional license) from another health profession ( 3 were CAM-related, 2 were nursing-related). In addition to being members of MNZ, 11 respondents (16.7\%) were also members of other professional associations.

\section{Workload}

Slightly more than half the respondents $(57.6 \%)$ self-reported practicing "full time" as massage therapists, with the practice of MT being the sole source of employment for 46 therapists $(69.7 \%)$. Therapists commonly practiced MT for $46-50$ weeks in a "typical year" (68.3\%), and nearly all (93.7\%) practiced massage for more than 40 weeks in the year. About two thirds of therapists $(65.7 \%)$ reported typically handling between 10 and 29 client visits per week (Figure 1) and a median of $16-20$ hours of direct client care per week (Figure 2).

\section{Practice Characteristics}

Practice settings varied. They included "solo practice" (57.6\%) and group practice "within a

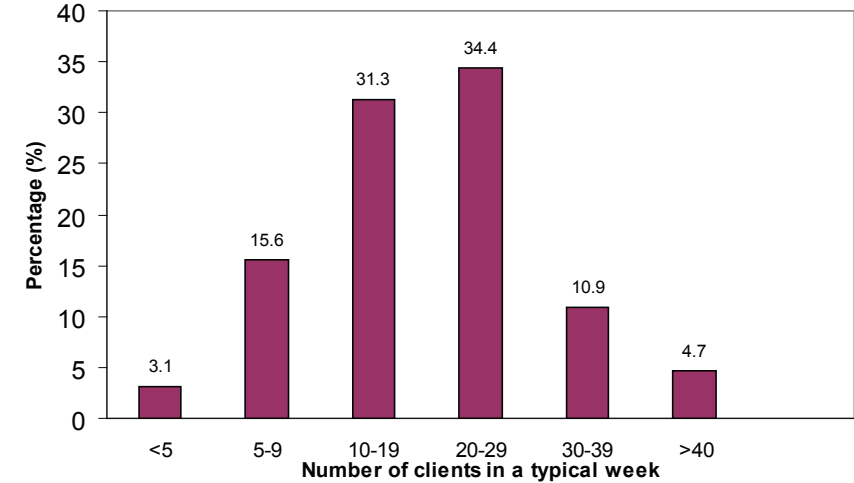

FIGURE 1. Survey of massage therapists: frequency distribution of client numbers in a typical week.

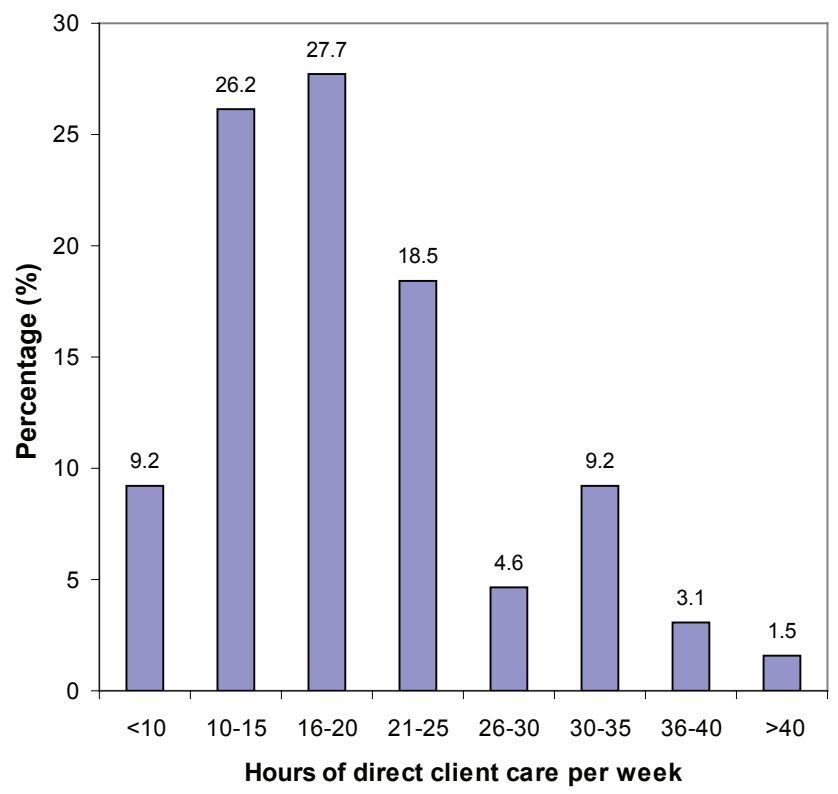

FIGURE 2. Survey of massage therapists: frequency distribution of hours of direct client care per week.

multidisciplinary group" (31.8\%) and "with a group of massage therapists" (18.2\%); however, about half the therapists $(54.5 \%)$ also practiced in more than one practice setting. Multidisciplinary group practices included a range of the following professions or professionals: osteopaths, beauticians, naturopaths, general practitioners, chiropractors, acupuncturists, counselors, social service providers, nurses, sports trainers, and physiotherapists. A range of practice locations and treatment durations were also identified (Table 1). The most frequent client fee per treatment was NZ\$60 per hour in a clinic and NZ\$1 per minute at a sports event or in the workplace. Variability in treatment durations within and between treatment locations were reported.

\section{Referral Patterns}

Most therapists $(89.2 \%)$ received referrals from the client's general practitioner or other health 
TABle 1. Massage Session Location and Duration $(N=66)$

\begin{tabular}{lcccc}
\hline $\begin{array}{c}\text { Location } \\
\text { (multiple responses } \\
\text { allowed) }\end{array}$ & $\begin{array}{c}\text { Respondents } \\
(\%)\end{array}$ & (n) & $\begin{array}{c}\text { Duration of treatment } \\
\text { Mode } \\
\text { (minutes) }\end{array}$ & $\begin{array}{c}\text { Range, } \\
\text { min-max } \\
\text { (minutes) }\end{array}$ \\
\hline $\begin{array}{c}\text { At a clinic } \\
\text { (not in your home) }\end{array}$ & 62.1 & 41 & 60 & $30-90$ \\
$\begin{array}{l}\text { At a clinic in your home } \\
\text { At a sports event }\end{array}$ & 47.0 & 31 & 60 & $60-90$ \\
$\begin{array}{l}\text { In the workplace } \\
\text { At the client's home }\end{array}$ & 27.3 & 18 & 15 & $10-180$ \\
At a health & 19.7 & 13 & 60 & $30-150$ \\
$\quad$ spa/beautician & 6.1 & 4 & 60 & $30-60$ \\
Other & & & & \\
\hline
\end{tabular}

a Eating disorder service, rest home, event (agriculture and produce show, for instance), hotel or resort, hospice.

professionals. Common sources of referral were physiotherapists $(67.2 \%)$, general practitioners $(60.3 \%)$, chiropractors $(34.5 \%)$, and osteopaths $(25.9 \%)$. Less common sources of referral included acupuncturists $(10.3 \%)$, podiatrists $(8.6 \%)$, personal trainers $(5.2 \%)$, hospital nurses $(3.4 \%)$, naturopaths $(3.4 \%)$, sports medicine specialists (3.4\%), the Accident Compensation Corporation $(1.7 \%)$, counselors $(1.7 \%)$, dentists (1.7\%), homeopaths $(1.7 \%)$, midwives $(1.7 \%)$, occupational health nurses $(1.7 \%)$, occupational therapists $(1.7 \%)$, orthopedic surgeons $(1.7 \%)$, other massage therapists $(1.7 \%)$, Pilates instructors $(1.7 \%)$, the Primary Health Organisation mental health initiative $(1.7 \%)$, psychologists $(1.7 \%)$, and psychotherapists $(1.7 \%)$. Similarly, therapists commonly referred their clients to a large number of health professionals (Table 2). General practitioners (69.7\%) were the professionals most commonly referred to, followed by osteopaths and physiotherapists.

\section{Treatment Characteristics}

A wide range of massage styles were offered (Table 3 ), and therapists reported treating a wide spectrum of symptoms (Table 4), including musculoskeletal, neurological, and psychological. Slightly more than one third of massage therapists $(n=24,36.4 \%)$ also practiced other forms of complementary therapy, such as acupressure, aromatherapy, Reiki, light therapy, herbal remedies and supplements, Bowen therapy, craniosacral therapy, lifestyle coaching, homeopathy, and reflexology. Of those 24 therapists, 21 reported combining CAM with their massage consultations. The most common client issues and conditions reported (Table 5) were musculoskeletal problems (98\%), especially back, neck/shoulder, and headache problems, and relaxation and stress reduction (95\%). The most common style of massage offered was "therapeutic
Table 2. Health Professionals to Which Massage Therapists Commonly Refer Clients $(N=66)$

\begin{tabular}{|c|c|c|}
\hline \multirow{2}{*}{$\begin{array}{c}\text { Type of professional } \\
\text { (multiple responses allowed) }\end{array}$} & \multicolumn{2}{|c|}{ Respondents } \\
\hline & $(\%)$ & (n) \\
\hline Doctor or general practitioner & 69.7 & 46 \\
\hline Osteopath & 66.7 & 44 \\
\hline Physiotherapist & 60.1 & 40 \\
\hline Homeopath or naturopath & 47.0 & 31 \\
\hline Acupuncturist & 43.9 & 29 \\
\hline Chiropractor & 43.9 & 29 \\
\hline Podiatrist & 36.4 & 24 \\
\hline Sports medicine specialist & 27.2 & 18 \\
\hline $\begin{array}{l}\text { Yoga, Feldenkrais, or } \\
\text { Alexander technique practitioner }\end{array}$ & 27.2 & 18 \\
\hline Counselor & 25.8 & 17 \\
\hline Craniosacral therapist & 25.8 & 17 \\
\hline Massage therapist & 18.2 & 12 \\
\hline Reflexologist & 9.1 & 6 \\
\hline Psychologist & 7.6 & 5 \\
\hline Traditional Chinese Medicine practitioner & 7.6 & 5 \\
\hline Occupational therapist & 6.1 & 4 \\
\hline Hospital or emergency room & 4.6 & 3 \\
\hline Aromatherapist & 1.5 & 1 \\
\hline Māori healer & 1.5 & 1 \\
\hline $\begin{array}{l}\text { None, nurse, Pacific healer, } \\
\text { Rongoā service provider, spiritual healer }\end{array}$ & 0.0 & 0 \\
\hline Other ${ }^{\mathrm{a}}$ & 25.8 & 17 \\
\hline
\end{tabular}

a Mentioned more than once: Pilates instructor, gym fitness or personal trainer, tai chi classes; mentioned once: BodyTalk therapist, CHEK coach, dietitian, beautician, herbalist, OrthoBionomy bodyworker, breathing specialist (Buteyko), Bowen Technique practitioner.

massage," followed by "relaxation massage," "sports massage," and "trigger-point therapy" respectively. Almost all therapists treated musculoskeletal symptoms - for example, "muscle pain," "stiffness," "tension," and "reduced mobility and strength." However, fatigue, nervous system symptoms (for example, "numbness," "altered sensation"), wellness symptoms (for example, "sleep disturbance," "sense of heaviness," "disconnection with body"), and psychological and mental health symptoms (for example, "sense of being out of balance," "anxiety or depression") had also been seen by more than $24 \%$ of the massage therapists at least once in the last 12 months.

Most massage therapists (98.5\%) undertook client assessment for their "typical client," with most commonly using the methods of "subjective assessment/ history taking" (98.5\%), "tissue assessment using palpation" (90.9\%), "postural assessment" (83.3\%), and "active range of motion" measures (78.8\%). "Passive range of motion" (69.7\%), "pain measures" $(68.2 \%)$, and "resisted tests" $(50 \%)$ were used by 
TABle 3. Styles of Massage Therapy Offered $(N=66)$

\begin{tabular}{|c|c|c|}
\hline \multirow{2}{*}{$\begin{array}{c}\text { Therapy style } \\
\text { (multiple responses allowed) }\end{array}$} & \multicolumn{2}{|c|}{ Respondents } \\
\hline & $(\%)$ & (n) \\
\hline $\begin{array}{l}\text { Therapeutic massage } \\
\text { (also remedial or deep-tissue) }\end{array}$ & 93.9 & 62 \\
\hline Relaxation massage & 92.4 & 61 \\
\hline Sports massage & 74.2 & 49 \\
\hline Trigger-point release & 74.2 & 49 \\
\hline Pregnancy massage & 63.6 & 42 \\
\hline Myofascial release (MFR) & 59.1 & 39 \\
\hline Neuromuscular therapy (NMT) & 51.5 & 34 \\
\hline Lymphatic drainage & 36.4 & 24 \\
\hline Onsite chair massage & 30.3 & 20 \\
\hline Aromatherapy & 27.3 & 18 \\
\hline Energy systems massage & 19.7 & 13 \\
\hline Other ${ }^{\mathrm{a}}$ & 34.9 & 23 \\
\hline
\end{tabular}

a Mentioned by 4: Bowen Technique; mentioned by 2 or 3: neurostructural integration, reflexology, Ortho-Bionomy, Reiki; mentioned by 1: active isolated stretching, holistic pulsing, hot stone massage, Indian head massage, muscle energy techniques, micromassage, mirimiri massage, infant massage instruction, Thai reflexology, tui $n a$ (Traditional Chinese Medicine acupressure).

TABle 4. Symptoms Treated by Massage Therapists in the Last 12 Months $(N=66)$

\begin{tabular}{llc}
\hline \multicolumn{1}{c}{$\begin{array}{c}\text { Symptom } \\
\text { (multiple responses allowed) }\end{array}$} & \multicolumn{2}{c}{ Respondents } \\
& $(\%)$ & (n) \\
\hline Muscle tightness, stiffness, or tension & 95.5 & 63 \\
Pain & 87.9 & 58 \\
Reduced movement or mobility & 84.9 & 56 \\
Trigger points & 81.8 & 54 \\
Fatigue & 68.2 & 45 \\
Reduced sense of relaxation & 68.2 & 45 \\
Numbness or change in sensation & 65.2 & 43 \\
Inability to sleep or sleep disturbance & 62.1 & 41 \\
Anxiety or depression & 60.6 & 40 \\
Reduced ability to function or perform & 60.6 & 40 \\
Sense of being out of balance & 57.8 & 38 \\
Reduced strength & 50.0 & 33 \\
Inflammation or swelling & 45.5 & 30 \\
Reduced circulation & 43.9 & 29 \\
Inability to work & 31.8 & 21 \\
Sense of heaviness & 30.3 & 20 \\
Disconnection with body & 24.2 & 16 \\
Helplessness & 13.6 & 9 \\
\hline
\end{tabular}

$50 \%$ or more of the therapists. Tests considered more "specialized" - that is, "muscle length tests" $(43.9 \%)$, "orthopedic tests" (22.7\%), "neurological tests" (19.7\%) —were less commonly used.
TABLE 5. Client Issues or Conditions Treated by Massage Therapists in the Last 12 Months $(N=66)$

\begin{tabular}{|c|c|c|}
\hline \multirow{2}{*}{$\begin{array}{c}\text { Condition } \\
\text { (multiple responses allowed) }\end{array}$} & \multicolumn{2}{|c|}{ Respondents } \\
\hline & $(\%)$ & (n) \\
\hline Back pain or problem & 98.5 & 65 \\
\hline Neck or shoulder pain or problem & 98.5 & 65 \\
\hline Headache or migraine & 98.5 & 65 \\
\hline Relaxation and stress reduction & 95.5 & 63 \\
\hline Regular recovery or maintenance massage & 89.4 & 59 \\
\hline Non-sporting injury & 87.9 & 58 \\
\hline $\begin{array}{l}\text { Disability, long-term illness, or } \\
\text { chronic condition }\end{array}$ & 83.3 & 55 \\
\hline Joint pain or stiffness & 83.3 & 55 \\
\hline Anxiety or depression & 80.3 & 53 \\
\hline Sports injury & 78.8 & 52 \\
\hline Wellness & 74.2 & 49 \\
\hline Arthritis or fibromyalgia & 71.2 & 47 \\
\hline Short-term illness or temporary condition & 69.7 & 46 \\
\hline Insomnia or trouble sleeping & 59.1 & 39 \\
\hline Spiritual well being & 36.4 & 24 \\
\hline Postoperative pain & 33.3 & 22 \\
\hline Lymphedema & 27.3 & 18 \\
\hline Other respiratory conditions & 22.7 & 15 \\
\hline Cancer & 21.2 & 14 \\
\hline Asthma & 19.7 & 13 \\
\hline Beauty or leisure routine & 13.6 & 9 \\
\hline
\end{tabular}

More than $95 \%$ of the therapists reported typically providing self-care recommendations (Table 6). "Increasing water intake" (94\%), "stretches" (88\%), "active movement" (79\%), "body awareness" (76\%), and "hot/cold therapy" (76\%) were the most common recommendations; resisted exercise $(46 \%)$ was less commonly recommended. Treatment effects or outcomes typically monitored for evaluating treatment effectiveness (Table 7) were client report $(97 \%)$, range of movement $(90.1 \%)$, pain level $(90.1 \%)$, and client satisfaction $(89.4 \%)$.

\section{Professional Issues}

A small number of key professional issues were also surveyed. Insurance cover for massage therapists is voluntary in New Zealand, and just over $50 \%$ of therapists $(52.3 \%)$ had professional indemnity, public liability, or similar insurance cover as a massage therapist for their practice. A quarter of the therapists surveyed $(25.8 \%)$ had experienced an occupational health issue or injury from delivering MT; injuries were to the "hand, wrist, thumb, forearm" (58.8\%), "shoulder, arm" (29.4\%), "neck, upper back" (17.6\%), "back" (17.6\%), "knees" (5.9\%), and "burnout" (5.9\%). 
Table 6. Self-Care Recommendations Typically Provided to Clients by Massage Therapists $(N=66)$

\begin{tabular}{lcc}
\hline \multicolumn{1}{c}{$\begin{array}{c}\text { Recommendation } \\
\text { (multiple responses allowed) }\end{array}$} & \multicolumn{2}{c}{ Respondents } \\
& $(\%)$ & $(\mathrm{n})$ \\
\hline Water intake, increase & 93.9 & 62 \\
Stretches & 87.9 & 58 \\
Movement exercise, active & 78.8 & 52 \\
Body awareness & 75.8 & 50 \\
Hot/cold therapy & 75.8 & 50 \\
Rest & 65.2 & 43 \\
Breath work & 63.6 & 42 \\
Movement exercise, resistance & 45.5 & 30 \\
Trigger point release & 45.5 & 30 \\
Visualization & 25.8 & 17 \\
None & 1.5 & 1 \\
Other & 22.7 & 15 \\
\hline
\end{tabular}

a Mentioned by 3: Anti-Flamme Herbal Creme (EBOS Healthcare, Auckland, NZ); mentioned by 2: homecare lymph movements, aromatherapy, diet or nutrition, "don't be a martyr to pain," ergonomic workstation, bike-fit setup, homeopathics, meditation; mentioned by 1: time for relaxation (sport reading self-time, for instance), postsession exercise (take-home sheet), reduce caffeine, refer to physio for strength work, relaxation techniques.

\section{DISCUSSION}

\section{Therapist Characteristics}

The results reported here are congruent with those in a previous study ${ }^{(20)}$ and from New Zealand census data $^{(29)}$, in that most therapists are female $(83 \%)$, NZ European $(76 \%)$, and a mean of 45.8 years of age; $6 \%$ were Māori. However, the median years in practice ( 7.0 years) was higher than that found in a US study conducted in the states of Washington and Connecticut (median: $4.0-5.0$ years) ${ }^{(20)}$, reflecting the large range in number of years in practice $(0.5-34$ years $)$.

Most therapists had completed their first massage qualification more than $6-10$ years earlier, but more than half of respondents had received their "highest massage qualification" in the preceding $1-5$ years, indicating some recency or up-skilling of qualifications. A massage diploma from a NZ massage education provider was the most common qualification, but massage baccalaureate training also featured among respondents. Other non-massage-related qualifications (for example, nursing) were common, perhaps because of the mean age of the therapists, previous life experience, a secondary or subsequent career, and compatibility with other hands-on caring professions.

A typical massage diploma qualification in NZ ranges from 1200 hours to 2400 hours in duration of training, with baccalaureate training in MT being 3600 hours. Research literacy is a key component of
TABLE 7. Treatment Effects or Outcomes Typically Monitored for Evaluating Effectiveness $(n=66)$

\begin{tabular}{|c|c|c|}
\hline \multirow{2}{*}{$\begin{array}{c}\text { Effect or outcome } \\
\text { (multiple responses allowed) }\end{array}$} & \multicolumn{2}{|c|}{ Respondents } \\
\hline & $(\%)$ & (n) \\
\hline Client reports "feels better" & 97.0 & 64 \\
\hline Range of movement & 90.1 & 60 \\
\hline Pain levels & 90.1 & 60 \\
\hline Client satisfaction & 89.4 & 59 \\
\hline Soft tissue texture or tone & 86.4 & 57 \\
\hline Energy and fatigue levels & 83.3 & 55 \\
\hline Function or performance & 78.8 & 52 \\
\hline Relaxation levels & 77.3 & 51 \\
\hline Activities of daily living & 71.2 & 47 \\
\hline Sleep patterns & 71.2 & 47 \\
\hline Stress levels & 68.2 & 45 \\
\hline Feelings and levels of wellbeing & 68.2 & 45 \\
\hline Role function in daily life and work & 63.6 & 42 \\
\hline Mood changes & 54.5 & 36 \\
\hline Circulation changes & 53.0 & 35 \\
\hline Onset of symptoms & 51.5 & 34 \\
\hline Ability to cope & 39.4 & 26 \\
\hline Sense of balance or connection & 34.9 & 23 \\
\hline Sense of hope or peace & 22.7 & 15 \\
\hline Sense of enablement & 21.2 & 14 \\
\hline Blood pressure & 13.6 & 9 \\
\hline Adjustment & 12.1 & 8 \\
\hline Anger levels & 10.6 & 7 \\
\hline Anxiety or depression levels & 4.5 & 3 \\
\hline None & 0.0 & 0 \\
\hline Other $^{\mathrm{a}}$ & 7.6 & 5 \\
\hline
\end{tabular}

a Change of any positive nature: diet changes, improvement in whatever symptoms they came in with, postural changes, self esteem, awareness of consciousness (being "present").

New Zealand-based baccalaureates ${ }^{(38)}$, but it is not a key component of New Zealand-based diplomas. As such, the ability of massage practitioners (predominantly holding diploma qualifications) to individually engage with the rapidly expanding knowledge base for $\mathrm{MT}^{(39)}$ may be hindered. Low levels of research literacy and capability were also identified in a survey of massage therapists in Alberta, Canada(40). This pattern of qualifications and skills may change as younger students perceive MT to be a viable career choice and as graduates from the two New Zealandbased baccalaureate degree programs in MT enter the MT workforce, MNZ, and postgraduate education.

\section{Practice Modes, Settings, and Therapy Characteristics}

Again, like the distribution of modes of practice reported by Cherkin et al. (20), "solo," but also "massage group practices" and "multidisciplinary practices," 
were common among most respondents; yet despite such similarities, fewer MNZ therapists practiced alone (58\% vs. $71 \%-73 \%)$ than did Washington and Connecticut therapists, and slightly more practiced in multidisciplinary settings.

Multidisciplinary practices in NZ involved a wide range of professionals. However, multidisciplinary settings typically involved working with other CAM providers, which accorded with results from the US study ${ }^{(20)}$; integration with conventional medical practices was rare. Within the NZ context, the concept of integrated care appears to be less well recognized and developed, as evidenced by a paucity of literature and minimal mention in health policy documents (the New Zealand Health Strategy, for instance). Against this background, multidisciplinary practice may simply reflect a need for cost-sharing, resulting from the number of hours of direct client care per week or the part-time or multi-setting nature of massage practice. The drivers for multidisciplinary practice (for example, cost-sharing or integrative care) therefore warrant further, more detailed, investigation to determine the reasons for and benefits of integration into multidisciplinary settings, and to provide insight into the evolvement of integrative care in New Zealand.

A range of practice settings was also evident. Dedicated non-home-based clinical facilities were most common (as they are with other more established musculoskeletal practitioners-for example, chiropractors, physiotherapists), but use of home-based clinics was also reported, perhaps again reflecting the part-time nature of MT. Similarly, massage was practiced in the sports, workplace, hospice, spa, hospitality, and mobile settings, suggesting an increase in employment opportunities within those settings, paralleling similar developments in the United States $^{(4,21)}$. The $30 \%$ of US therapists practicing at a sports event contrasted notably with the $4 \%$ reported in the NZ Department of Labour survey ${ }^{(29)}$; the foregoing differences may be a result of the sample population or may indicate a change in trend.

One notable difference between New Zealand and the United States was an apparent lack of MT practice in the NZ hospital setting. This difference may be in part a result of a contemporary practice of nurses and physiotherapists in NZ hospitals incorporating some MT care, or it may reflect a slow uptake of integrative care in New Zealand. It may also result from differences in public and private hospital care between the two countries, or a lack of a formal licensing or regulatory system $^{(41)}$ for the practice of MT in New Zealand. Also different was the pattern of spa work: In 2008 in the United States, 29\% of therapists worked in a spa ${ }^{(21)}$; only $6 \%$ of MNZ therapists worked in the spa/beauty therapy setting. Such differences may be attributable to the sample surveyed (rather than being representative of the wider population of massage therapists), or they may indicate that massage in the spa setting is less well developed in New Zealand at this time.
The commonly used massage styles and most frequent issues or conditions seen by massage therapists were again similar to those reported in US-based studies $^{(8,42)}$, suggesting some cross-national congruency both in massage styles and massage client issues or conditions. Although therapists in the present study were not specifically asked the number of styles they typically used for a single client, a range of 26 different massage or bodywork styles were collectively identified by survey respondents. Within the reported massage styles offered, there was evidence to support all four principal goals of treatment - relaxation massage, clinical massage, movement re-education, and energy work-identified by Sherman and colleagues $^{(6)}$. Approximately $14 \%$ of therapists also held annual practicing certificates (licenses) for other CAM modalities or for nursing: $36 \%$ practiced other forms of complementary therapies, with $32 \%$ combining CAM with their massage consultations. Clearly then, therapists may blend a number of different health philosophies and practices (for example, assessment, clinical reasoning, styles of massage) into their practice of MT, and the patterns of practice reported may therefore not reflect purely those of MT.

Assessment techniques and self-care recommendations given to clients (most commonly, increased water intake, stretches, and active movement) were also similar to those reported by Sherman et al. ${ }^{(34)}$; however, further research investigating the specific advice dispensed is needed, given that many clients self-refer, receive MT as a standalone therapy, experience variability in the duration of treatments, and value the education and information sharing $(36,37)$ provided by therapists. Further research into the "whens" and "whys" that therapists are using as assessment methods is required. In addition, investigation is needed regarding the suitability of assessment methods, measures of effectiveness, and MT training in relation to the symptoms and conditions being treated by therapists. Reinforcing that view is the finding that, although most therapists monitored treatment effects or outcomes, commonly used measures of treatment effectiveness were "client reports 'feels better'," "pain levels," and client satisfaction. The authors suggest that massage therapists as health care service providers, have to demonstrate effective measurement of their interventions, not only as a prerequisite to providing appropriate interventions to their clients, but also for demonstration of quality services, accountability, and continual performance improvement. That need is even more pressing if MT service providers want to seek external funder reimbursement for services; current effectiveness measures may be inadequate.

\section{Massage Therapy as an Occupation}

The present findings indicated that MT was practiced by therapists as either a full- or part-time 
occupation, which is similar to findings reported by Cherkin and colleagues ${ }^{(20)}$ that MT was commonly practiced for $46-50$ weeks per annum. However, the terms "full-time" and "part-time" were not defined and responses to subsequent qualifying questions (self-reported measures of "hours of direct client care" and "number of clients visits per week") suggest that the practice of MT may not equate to a 40hour work week for a large number of respondents. The physical nature of MT, the availability of clients, and a desire for part-time work or access to clientfriendly appointment times may limit the hours of work per week. The move by some therapists to integrate other CAM therapies that are less physically demanding (for example, aromatherapy, Reiki, light therapy, herbal remedies and supplements, craniosacral therapy, lifestyle coaching, homeopathy) may provide an opportunity to increase hours per week associated with the additional skills, to create more potential diversity in their client market, and to lessen physical demands. Future research into the workload of massage therapists needs to define "full-time" and "part-time" and to account for direct client care and various non-client-care aspects of the job.

The most frequent client fee per treatment was NZ\$60 per hour in a clinic. Massage sessions are commonly privately paid and medical insurance reimbursement or other third-party payments (for example, from an employer or government) are negligible (Smith JM. Massage therapy services for health needs: drivers, utilisation, culture of care, and practice patterns of massage therapy in NZ. PhD thesis; University of Otago, Dunedin, NZ; 2009). These factors of cost and payment source provide an important contextual element to the massage user demographic of a higher-than-average household income (Smith JM. Massage therapy services for health needs: drivers, utilisation, culture of care, and practice patterns of massage therapy in NZ. PhD thesis; University of Otago, Dunedin, NZ; 2009) and may also partly explain the proactive and health conscious approach of massage users ${ }^{(37)}$.

Notably, the commonly used massage styles (for example, therapeutic massage, neuromuscular therapy) are more physically demanding than other styles of MT, reinforcing the physical nature of the job. It is therefore not surprising to see that $26 \%$ of therapists had experienced an occupational health issue or injury arising from delivering MT - and in the regions reported by Buck and colleagues ${ }^{(43)}$ as being dominant in MT: that is, back and upper extremities. It was not the aim of the current survey to fully investigate therapist injuries resulting from the job, and questions relating to self-care and maintenance, and proper massage therapist posture were therefore not asked. However, the present survey does indicate a likelihood of occupational injury in massage therapists (for example, musculoskeletal pain and discomfort) associated with the practice of MT. Despite injury rates being much lower than those reported by Canadian massage therapists ${ }^{(44)}$ and physiotherapists ${ }^{(45)}$, this area needs monitoring for the sustainability of the profession and the health of the massage professional.

\section{Referral Patterns}

Of respondents to the current survey, $60 \%$ reported receiving referrals from general practitioners (GPs), suggesting that, although massage therapists cannot bill the public health system for MT services, MT could be seen as being part of the wider health system in New Zealand. Referrals were also commonly received from a broad range of CAM and other conventional health care providers, indicating a wide and active referral network. In addition, massage therapists referred to other massage therapists; however, it is not known whether those referrals reflect unavailability of the therapist, inability of the therapist to treat the condition (that is, because of a lack of expertise or skills), or client relocation. Given that MT use in New Zealand is self-funded (Smith JM. Massage therapy services for health needs: drivers, utilisation, culture of care, and practice patterns of massage therapy in NZ. $\mathrm{PhD}$ thesis; University of Otago, Dunedin, NZ; 2009), it would be useful to explore the networking strategies used by massage therapists and the extent of between-provider communication sharing about client management. In addition, further exploration of the reasons for referral by massage therapists is warranted given the range of symptoms with which clients may present, the limited assessment and outcome measurement practices, and the level of training of the therapists.

In US integrative health care clinics, MT is commonly offered as part of the CAM package of therapies ${ }^{(46)}$. Integrative medicine, with its focus on "health and healing ... [viewing] patients as whole people with minds and spirits as well as bodies"(47) (p. 119) is congruent with the culture of care of MT practice in New Zealand ${ }^{(36)}$. Given the position of integrative medicine in the United States and the potential future role of GPs in informed referral to $\mathrm{CAM}^{(48)}$, the referral patterns described in the present work suggest that new opportunities within integrative care also potentially exist for the NZ massage profession.

\section{Limitations}

The results reported here are based on self-reports of practice by therapists rather than on analyses of client or visit records, and despite obtaining access to trained MNZ-registered massage therapists, it is not known whether the results are representative of all MNZ members or of other massage therapists within New Zealand. More massage therapists in 
New Zealand are not members of MNZ than are members, and their practice may be different. However, given that a number of trained massage therapists in NZ (who are not MNZ members) would have training credentials similar to the credentials of those surveyed, practice patterns may also be similar.

Care must also be taken when interpreting the descriptive statistics, because the margin of error associated with the data is a larger than might be desirable. Nevertheless, this first survey of MNZ massage therapists provides a useful insight into characteristics of MT practice by this group of massage professionals. Although the numbers surveyed are small $(n=66)$, national representation was strong, and the response rate of $71.7 \%$ was high, reflecting the practice pattern of $26 \%$ of the current target population. Only $9 \%$ of MNZ therapists surveyed were certificate-trained and therefore qualified at the CMT level to provide relaxation massage. However, relaxation massage was commonly practiced by RMTs (diploma-trained), and so the findings may reflect the practice of both relaxation and therapeutic massage, but from the educational and experience base of a diploma-trained therapeutic (remedial) massage therapist.

\section{SUMMARY}

This is the first investigation into the practice patterns of trained MNZ massage therapists throughout New Zealand. It provides a useful descriptive account of MT service provision that will help inform the massage and CAM industries in New Zealand, as well as potential funders, workforce planners, and policymakers involved in conventional, CAM, or integrative health care in the country. The information provided should be informative to New Zealand health care providers interested in advising their patients about MT. It also contributes important information to the sparse international literature describing MT practice, adding to the global picture of current practice of this popular CAM therapy.

\section{CONFLICT OF INTEREST NOTIFICATION}

JMS is a massage therapist and was a member of Massage New Zealand before and during the time that the research was conducted. A University of Otago Postgraduate Scholarship and a University of Otago Postgraduate Publishing Bursary supported Dr. Smith's research.

\section{COPYRIGHT}

Published under the CreativeCommons AttributionNonCommercial-NoDerivs 3.0 License.

\section{REFERENCES}

1. Yates J. A Physician's Guide to Therapeutic Massage. 3rd ed. Toronto, ON: Curties-Overzet Publishing; 2004.

2. Tuchtan CC, Tuchtan VM, Stelfox D. Foundations of Massage. 2nd ed. Marrickville, NSW, Australia: Churchill Livingstone; 2004.

3. Calvert RN. The History of Massage: An Illustrated Survey from Around the World. Rochester, VT: Healing Arts Press; 2002.

4. Fritz S. Mosby's Fundamentals of Therapeutic Massage. 4th ed. St. Louis, MO: Mosby; 2006.

5. Menard M. Methodological issues in the design and conduct of massage therapy research. In: Rich GJ, ed. Massage Therapy: The Evidence for Practice. London, UK: Mosby/Elsevier; 2002.

6. Sherman KJ, Dixon MW, Thompson D, Cherkin DC. Development of a taxonomy to describe massage treatments for musculoskeletal pain. BMC Complement Altern Med. 2006; 6:24.

7. Moyer CA, Rounds J, Hannum JW. A meta-analysis of massage therapy research. Psychol Bull. 2004; 130(1):3-18.

8. Cherkin DC, Deyo RA, Sherman KJ, Hart LG, Street JH, Hrbek A, et al. Characteristics of visits to licensed acupuncturists, chiropractors, massage therapists, and naturopathic physicians. J Am Board Fam Pract. 2002; 15(6):463-472.

9. Furlan $\mathrm{AD}$, Brosseau L, Imamura M, Irvin E. Massage for low back pain. Cochrane Database Syst Rev. 2002; (2):CD001929.

10. Lawler S. Massage therapy and complementary and alternative medicine: attitudes and use among general practitioners and patients in Auckland, New Zealand. N Z Fam Pract. 2004; 31(4):229-238.

11. Ernst E. Does post-exercise massage treatment reduce delayed onset muscle soreness? A systematic review. Br J Sports Med. 1998; 32(3):212-214.

12. Moraska A. Sports massage: a comprehensive review. J Sports Med Phys Fitness. 2005; 45(3):370-380.

13. Weerapong P, Hume PA, Kolt GS. The mechanisms of massage and effects on performance, muscle recovery and injury prevention. Sports Med. 2005; 35(3):235-256.

14. Grealish L, Lomasney A, Whiteman B. Foot massage: a nursing intervention to modify the distressing symptoms of pain and nausea in patients hospitalized with cancer. Cancer Nurs. 2000; 23(3):237-243.

15. Remington R. Calming music and hand massage with agitated elderly. Nurs Res. 2002; 51(5):317-323.

16. Foster NE, Thompson KA, Baxter GD, Allen JM. Management of nonspecific low back pain by physiotherapists in Britain and Ireland. A descriptive questionnaire of current clinical practice. Spine (Phila Pa 1976). 1999; 24(13):1332-1342.

17. Galloway SD, Watt JM. Massage provision by physiotherapists at major athletics events between 1987 and 1998. Br J Sports Med. 2004; 38(2):235-237.

18. Fellowes D, Barnes K, Wilkinson S. Aromatherapy and massage for symptom relief in patients with cancer. Cochrane Database Syst Rev. 2004; (2):CD002287.

19. Mehling WE, Jacobs B, Acree M, Wilson L, Bostrom A, West $\mathrm{J}$, et al. Symptom management with massage and acupuncture in postoperative cancer patients: a randomized controlled trial. J Pain Symptom Manage. 2007; 33(3):258-266.

20. Cherkin DC, Deyo RA, Sherman KJ, Hart LG, Street JH, Hrbek A, et al. Characteristics of licensed acupuncturists, 
chiropractors, massage therapists, and naturopathic physicians. $J$ Am Board Fam Pract. 2002; 15(5):378-390.

21. American Massage Therapy Association. Who gets a massage, where and why? American Massage Therapy Association website. http://www.amtamassage.org/articles/2/PressRelease/ detail/2185\#whogetsmassage. Published 2009. Accessed June 27, 2009.

22. Brennan MK, DeBate RD. The effect of chair massage on stress perception of hospital bedside nurses. J Bodyw Mov Ther. 2006; 10(4):335-342.

23. Katz J, Wowk A, Culp D, Wakeling H. Pain and tension are reduced among hospital nurses after on-site massage treatments: a pilot study. J Perianesth Nurs. 1999; 14(3):128-133.

24. Kozak LE, Kayes L, McCarty R, Walkinshaw C, Congdon $\mathrm{S}$, Kleinberger J, et al. Use of complementary and alternative medicine (CAM) by Washington state hospices. Am J Hosp Palliat Care. 2009; 25(6):463-468.

25. Ministerial Advisory Committee on Complementary and Alternative Health. Complementary and Alternative Health Care in New Zealand. Advice to the Minister of Health. Wellington, NZ: Ministry of Health; 2004.

26. Massage New Zealand. Welcome to Massage New Zealand. Massage New Zealand website. http://www.massagenewzealand. org/. Published n.d. Updated n.d. Accessed June 6, 2009.

27. Smith J, Sullivan SJ, Baxter GD. Massage therapy: more than a modality. N Z J Physiother. 2010; 38(2):44-51.

28. Massage New Zealand. FAQ for NZ members: Why should I belong to Massage New Zealand? Massage New Zealand website. http://massagenewzealand.org.nz/membership/ faq-for-nz-members/. Published n.d. Updated n.d. Accessed June 6, 2009.

29. Department of Labour. Jobs and Tertiary Education Indicators Tool [Occupation: Massage Therapist]. New Zealand Department of Labour website. http://www.dol.govt.nz/services/LMI/ tools/jtei.asp. Published n.d. Updated n.d. Accessed 2009.

30. Barnes PM, Powell-Griner E, McFann K, Nahin RL. Complementary and alternative medicine use among adults: United States 2002. Adv Data. 2004; (343):1-19.

31. Economic and Social Research Council. Northern Ireland Life and Times Survey [main questionnaire]. University of Ulster, ARK Northern Ireland website. http://www.ark.ac.uk/ nilt/2005/main05.pdf. Published n.d. Updated n.d. Accessed November 30, 2007.

32. Massage New Zealand. Massage styles. Massage New Zealand website. http://www.massagenewzealand.org./ index.php? page $=$ massage style [revised content now available at http://massagenewzealand.org.nz/answers/ massage-techniques/]. Published n.d. Updated n.d. Accessed 2007 (original) and February 18, 2011 (revised).

33. Sherman KJ, Cherkin DC, Eisenberg DM, Erro J, Hrbek A, Deyo RA. The practice of acupuncture: who are the providers and what do they do? Ann Fam Med. 2005; 3(2):151-158.

34. Sherman KJ, Cherkin DC, Kahn J, Erro J, Hrbek A, Deyo RA, et al. A survey of training and practice patterns of massage therapists in two US states. BMC Complement Altern Med. 2005; 5:13.
35. Zollman C, Vickers A. ABC of complementary medicine. Complementary medicine and the patient. BMJ. 1999; 319(7223):1486-1489.

36. Smith JM, Sullivan SJ, Baxter GD. The culture of massage therapy: valued elements and the role of comfort, contact, connection and caring. Complement Ther Med. 2009; 17(4):181-189.

37. Smith JM, Sullivan SJ, Baxter GD. Massage therapy services for healthcare: a telephone focus group study of drivers for clients' continued use of services. Complement Ther Med. 2009; 17(5-6):281-291.

38. Smith J, Smith D. Letter to the editor. Int J Ther Massage Bodyw. 2009; 2(3):31. http://journals.sfu.ca/ijtmb/index.php/ ijtmb/article/view/57/67. Published September 2009. Accessed March 21, 2010.

39. Moyer CA, Dryden T, Shipwright S. Directions and dilemmas in massage therapy research: a workshop report from the 2009 North American Research Conference on Complementary and Integrative Medicine. Int J Ther Massage Bodyw. 2009; 2(2):15-26. http://journals.sfu.ca/ijtmb/index.php/ijtmb/article/ view/51/64. Published June 2009. Accessed March 21, 2010.

40. Suter E, Vanderheyden LC, Trojan LS, Verhoef MJ, Armitage GD. How important is research-based practice to chiropractors and massage therapists? J Manipulative Physiol Ther. 2007; 30(2):109-115.

41. Duke K. A century of CAM in New Zealand: a struggle for recognition. Complement Ther Clin Pract. 2005; 11(1):11-16.

42. Lee ACC, Kemper KJ. Practice patterns of massage therapists. J Altern Complement Med. 2000; 6(6):527-529.

43. Buck FA, Kuruganti U, Albert WJ, Babineau M, Orser S, Currie-Jackson N. Muscular and postural demands of using a massage chair and massage table. J Manipulative Physiol Ther. 2007; 30(5):357-364.

44. Albert WJ, Currie-Jackson N, Duncan CA. A survey of musculoskeletal injuries amongst Canadian massage therapists. J Bodyw Mov Ther. 2008; 12(1):86-93.

45. Cromie JE, Robertson VJ, Best MO. Work-related musculoskeletal disorders in physical therapists: prevalence, severity, risks, and responses. Phys Ther. 2000; 80(4):336-351.

46. Kreitzer MJ, Kligler B, Meeker WC. Health professions education and integrative healthcare. Explore (NY). 2009; 5(4):212-227.

47. Rees L, Weil A. Integrated medicine. BMJ. 2001; 322(7279): 119-120.

48. Ben-Arye E, Frenkel M, Klein A, Scharf M. Attitudes toward integration of complementary and alternative medicine in primary care: perspectives of patients, physicians and complementary practitioners. Patient Educ Couns. 2008; 70(3):395-402.

Corresponding author: Jo Smith, New Zealand Massage Therapy Research Centre, Southern Institute of Technology, Private Bag 90114, Invercargill 9840 New Zealand.

E-mail: jo.smith@sit.ac.nz 